\title{
Screening for pulmonary hypertension secondary to pulmonary tuberculosis
}

It is likely that some patients who have had pulmonary tuberculosis (PTB) will go on to develop pulmonary hypertension (PH). PTB affects many compartments of the lung with injury to airways, parenchyma and loss of pulmonary vascular bed. The possible association between PTB and PH has been suggested by several authors. ${ }^{[1,2]}$ To date, however, there has been a paucity of data confirming this suspicion, with a study ${ }^{[3]}$ from India showing that $15 \%$ of patients with PH had evidence of previous PTB.

This issue of the AJTCCM contains the results of a pilot study of patients with previously treated PTB who were evaluated for the presence of $\mathrm{PH} .{ }^{[4]}$ The 20 patients included were screened for many other recognised causes of $\mathrm{PH}$, and subjected to clinical, electrocardiographical, radiological, pulmonary function and echocardiographical testing. None of the patients had symptoms of dyspnoea, and there were no clinical findings suggestive of $\mathrm{PH}$. Approximately one-third had electrocardiographical changes, and $85 \%$ had at least one chest radiographical feature compatible with PH. Pulmonary function was within normal limits. All patients underwent echocardiography and none of them were found to have elevated pulmonary artery pressures.

This small pilot study does not exclude the possibility of $\mathrm{PH}$ as a consequence of $\mathrm{PTB}$, but raises the question of which patients, of the many who have had PTB, should undergo further evaluation. Most algorithms for screening for $\mathrm{PH}$ approach this issue by suggesting clinical suspicion, followed by echocardiography. ${ }^{[-7]}$ Dyspnoea is the most prominent symptom in $\mathrm{PH}^{[8]}$ and the absence of this, perhaps, explains the results of this pilot study. Clinical examination, electrocardiography and chest radiology are likely to be helpful in more severe disease. Chest radiology with enlargement of the pulmonary artery associated with right ventricular enlargement, or peripheral pruning, had a high sensitivity and specificity for $\mathrm{PH}$ in patients with a $50 \%$ pre-test probability of $\mathrm{PH} \cdot{ }^{[9]}$ Kalla et al. ${ }^{[4]}$ describe enlarged pulmonary arteries in $75 \%$ and pruning in $25 \%$ of patients, but do not mention whether these were combined. Echocardiography remains the most helpful screening tool, with chest computed tomography, ventilation-perfusion scans and right heart catheterisation remaining essential investigations once the diagnosis of $\mathrm{PH}$ is likely. ${ }^{[5]}$

$\mathrm{PH}$ secondary to PTB is likely to be multifactorial in origin. The prevalence remains unknown, and further studies to ascertain the true prevalence remain important. As a start, future studies should use symptoms, particularly dyspnoea, as an initial screening test to enhance detection.

Richard Raine, MB ChB, MMed (Med), FCP (SA)

Respiratory Clinic, Department of Medicine, Faculty of Health

Sciences, University of Cape Town, South Africa

richard.raine@uct.ac.za

Afr J Thoracic Crit Care Med 2020;26(4):128. https://doi. org/10.7196/AJTCCM.2020.v26i4.129

1. Allwood BW, Maarman GJ, Kyriakakis CG, Doubell AF. Post-pulmonary tuberculosis complications in South Africa and a potential link with pulmonary hypertension: Premise for clinical and scientific investigations. S Afr Med J 2018;108(7):529. https:// doi.org/10.7196/samj.2018.v108i7.13359

2. Verma AK. Tuberculosis and pulmonary hypertension: Commentary. Lung India 2016;33(2):232-233. https://doi.org/10.4103/0970-2113.177455

3. Bhattacharyya P, Saha D, Bhattacherjee PD, Das SK, Bhattacharyya PP, Dey R. Tuberculosis associated pulmonary hypertension: The revelation of a clinical observation. Lung India 2016;33(2):135-139. https://doi.org/10.4103/0970-2113.177433

4. Kalla IS, Miri A, Seedat F. Occult pulmonary arterial hypertension in patients with previous pulmonary tuberculosis. Afr J Thoracic Crit Care Med 2020;26(4):133-137. https://doi.org/10.7196/AJTCCM.2020.v26i4.110

5. Frost A, Badesch D, Gibbs JSR, et al. Diagnosis of pulmonary hypertension. Eur Respir J 2019;53(1):1801904. https://doi.org/10.1183/13993003.01904-2018

6. Rich JD, Rich S. Clinical diagnosis of pulmonary hypertension. Circulation 2014;130(20):1820-1830. https://doi.org/10.1161/CIRCULATIONAHA.114.006971

7. Sahay S. Evaluation and classification of pulmonary arterial hypertension. J Thoracic Dis 2019;11(Suppl 14):S1789-S1799. https://doi.org/10.21037/jtd.2019.08.54

8. Brown LM, Chen H, Halpern S, et al. Delay in recognition of pulmonary arterial hypertension: Factors identified from the REVEAL Registry. Chest 2011;140(1):19-26.

9. Miniati M, Monti S, Airo E, et al. Accuracy of chest radiography in predicting pulmonary hypertension: A case-control study. Thromb Res 2014;133(3):345-351. 